\title{
Método história oral de vida: contribuições para a pesquisa qualitativa em terapia ocupacional*
}

\author{
Oral method life history: contributions for the \\ qualitative research in occupational therapy
}

Valdir Pierote Silva ${ }^{1}$, Denise Dias Barros ${ }^{2}$

SILVA, V. P.; BARROS, D. D. Método história oral de vida: contribuições para a pesquisa qualitativa em terapia ocupacional. Rev. Ter. Ocup. Univ. São Paulo, v. 21, n. 1, p. 68-73, jan./abr. 2010.

RESUMO: A história oral de vida é uma dos métodos que compõem o campo da pesquisa qualitativa, a qual se preocupa com significados e sentidos das ações e relações entre pessoas ou grupos. Este artigo trata de descrever e analisar os aportes que este método, sistematizado no Brasil principalmente pelo historiador José Carlos Sebe Bom Meihy e seus colaboradores, pode fornecer às pesquisas em Terapia Ocupacional e aos campos afins. Para tanto, realiza-se uma discussão sobre memória para, então, descrever o referido método e, finalmente, discutir a história oral de vida no âmbito da pesquisa em Terapia Ocupacional.

DESCRITORES: Narração. Memória. Pesquisa. Pesquisa qualitativa. Experimentação humana terapêutica/história.

\footnotetext{
Esse artigo tem como base o estudo metodológico realizado para a iniciação científica "Deslocamentos e histórias de vida: trajetória da comunidade quilombola Riacho das Pedras atingida pela construção da Barragem Luiz Vieira em Rio de Contas-BA" (PIEROTE-SILVA, 2009), que contou com o apoio da FAPESP e do Núcleo Interdisciplinar do Imaginário e Memória (NIME-USP).

1. Terapeuta Ocupacional formado pela Faculdade de Medicina da Universidade de São Paulo (FMUSP).

2. Doutora em Sociologia pela Faculdade de Filosofia e Ciências Humanas da USP, docente do curso de Terapia Ocupacional do Departamento de Fisioterapia, Fonoaudiologia e Terapia Ocupacional da FMUSP, pesquisadora do NIME-USP e do Projeto METUIA-USP.

Endereço para correspondência: Projeto METUIA - Núcleo São Paulo. Rua Cipotânea, 51. Cidade Universitária. 05360160. E-mail: v.pierote@hotmail.com
} 
SILVA, V. P.; BARROS, D. D. Método história oral de vida. Rev. Ter. Ocup. Univ. São Paulo, v. 21, n. 1, p. 68-73, jan./abr. 2010.

\section{INTRODUÇÃO}

$\mathrm{N}$ os últimos anos, a Terapia Ocupacional no Brasil tem empreendido diversos estudos de abordagem qualitativa, em especial trabalhos que adotam a história de vida como método (BRUNELLO, 1998; LOPES et al., 2002; BARROS, 2004A, 2008; BELLENZANI; MALFITANO, 2006; GALVANI, 2008; PIEROTE-SILVA, 2009). Essa característica talvez seja resultado de uma relação histórica com as ciências humanas e de uma preocupação constante em contextualizar, cultural e socialmente, as pessoas, grupos e suas práticas. Entende-se assim que a preocupação de parte significativa dos estudos tenha como foco a apreensão dos significados, motivações, emoções e valores para elucidar atitudes, comportamentos e práticas sociais. Todas estas correspondem a dimensões do real, que necessitam ser compreendidas em perspectivas qualitativas de entendimento dos fenômenos sociais. Os dados tornados quantificáveis e as análises estatísticas não são suficientes para o entendimento de vastas dimensões da existência como os processos relacionais, subjetivos e intersubjetivos, simbólicos, históricos e seus contextos sociais. Trata-se, segundo Minayo (2007), sobretudo de descrever e analisar os significados e sentidos de ações e relações de pessoas ou grupos.

A história de vida, um dos métodos que compõem o campo mais amplo da pesquisa qualitativa e mais especificamente da história oral, constitui-se como um dos instrumentos fundamentiais das ciências humanas, sendo utilizadado atualmente por diversos sociólogos, antropólogos, historiadores, psicólogos e, mais recentemente, por terapeutas ocupacionais. Expressão polissêmica, a história de vida pode conotar metodologia de estudo na pesquisa social, procedimento clínico, registro estrito de biografias e de depoimentos pessoais - sejam eles escritos ou orais. Sendo assim, ela recobre narrativas e relatos - sobre um fenômeno, um acontecimento ou um período de tempo -, colhidos por meio de estudo documental, depoimentos e entrevistas (gravadas em áudio e/ou vídeo) as quais podem ser trabalhadas por meio de diversos procedimentos e técnicas.

Adotada sob inúmeras perspectivas e empregada e estudada por vários autrores tanto no Brasil como em outros países (LEWIS, 1979; BRIOSCHI; TRIGO, 1987; QUEIROZ, 1988; THOMPSON, 1992; BOSI, 1994; THOMAS; ZNANIECKI, 2004; FERNANDES, 2007), a história de vida apresenta entendimentos diversos. No entanto, a discussão proposta neste artigo refere-se especificamente a compreenção sistematizada principalmente pelo historiador José Carlos Sebe Bom Meihy e seus colaboradores (MEIHY, 2005; MEIHY; HOLANDA, 2007) do Núcleo de História Oral da Universidade de São Paulo (NeHo-USP), a qual denominaram de "história oral de vida", adicionando ao termo "oral" na expressão para refoçar o foco da oralidade nesse tipo de método. Tal perspectiva forma, portanto, o ancoradouro a partir do qual se descreverá e se analisará os aportes que a história oral de vida pode fornecer aos estudos em Terapia Ocupacional e campos afins.

\section{Memória e a sigularidade de uma trajetória singular}

Quem conta uma história, faz necessariamente apelo a sua memória e a trabalha para dar inteligibilidade à experiência e para ressignificar o vivido, conferindo-lhe uma logicidade que constrói, organiza e justifica seu ponto de vista. Ao relatar sua história de vida, o narrador concatena parte dos fatos e eventos que a constituíram de acordo com a situação e com as relações que ocorrem durante a própria narrativa. No entanto, nem sempre tal processo é consciente, ele contém continuamente dimensões que escapam ao próprio narrador. A memória é processual e situada, ela vai construindo-se e desenhando sentidos (sempre parcelares) na relação que estabelece entre experiência passada, presente e projeção de futuro (desejo) e, igualmente, com a subjetividade daquele que escuta, num processo dialético entre a subjetividade do ouvinte e a do narrador. Para Bardin (1997), na elaboração do discurso

é feito um trabalho, é elaborado um sentido e são operadas transformações. O discurso não é transposição transparente de opiniões, de atitudes e de representações que existam de modo cabal antes da passagem à forma linguageira. $\mathrm{O}$ discurso não é um produto acabado mas um momento num processo de elaboração, com tudo o que isso comporta de contradições, de incoerências, de imperfeições (p.170).

Nesse sentido, Garcia Márquez (2003) nos convida à reflexão na epígrafe do seu livro autobiográfico "Viver para contar", na qual escreve que a vida não é o que a gente viveu, e sim o que a gente recorda e como recorda para contá-la. Para tornar a realidade inteligível, portanto, as pessoas necessitam organizá-la por meio de narrações que estão em permanente movimento de intercâmbio e em conexão com outras histórias. Contudo, apesar da realidade ser descontinua e composta por elementos imprevistos, sem razão ou conexão, ainda é muito comum o pensamento de que a vida constitui um todo, um conjunto coerente e orientado, que pode e deve ser apreendido como expressão unitária de uma "intenção" subjetiva e objetiva (...) (BOURDIEU, 2000, p.184). Tal pensamento 
SILVA, V. P.; BARROS, D. D. Método história oral de vida. Rev. Ter. Ocup. Univ. São Paulo, v. 21, n. 1, p. 68-73, jan./abr. 2010.

parte de uma lógica cartesiana, que considera a vida como uma evolução contínua e linear na qual acontecimentos seqüenciais e coerentes se concatenam. Segundo o sociólogo Pierre Bourdieu (IDEM), esse entendimento unidirecional da existência pode ser superado a partir da substituição da idéia de linearidade pela noção de trajetória, a qual define como uma série de posições ocupadas num espaço em que um agente é ele próprio um devir, sujeito a incessantes transformações e não um indivíduo posto em linha evolutiva.

Nessa perspectiva, o relato de uma trajetória singular é compreendido pelo prisma da imprecisão, da incerteza, das contradições e da dúvida. Não há a busca por uma verdade absoluta, por um itinerário coeso, mas sim o registro de uma versão particular de sentimentos e acontecimentos históricos narrados por uma determinada pessoa. Como ressalta Benjamin (1993), articular historicamente o passado não significa conhecê-lo "como ele foi de fato". Significa apropriar-se de uma reminiscência, tal como ela relampeja no momento de um perigo (p. 224). E essa reminiscência que dá substância a qualquer trajetória singular é a memória: conceito abstrato, difícil de ser definido, mas que constitui importante fonte de impressões, registros e pontos de vista.

A memória possui uma grande variedade de definições: faculdade de lembrar, de reter impressões e idéias, lembrança, recordação, reminiscência. Costuma também ser dividida em individual e coletiva, apesar das duas formas se relacionarem de modo continuo e intenso. Para Meihy (2005), a primeira é de caráter pessoal e psicológico, pois se relaciona a experiências particulares e possui um aporte orgânico (cérebro) e cognitivo (mente); já a memória coletiva é de ordem fundamentalmente cultural e transcendente, uma vez que compreende elementos externos que marcam a identidade de um grupo específico. As memórias são organizadas segundo uma lógica subjetiva que seleciona e articula elementos que nem sempre correspondem aos fatos concretos, objetivos e materiais (MEIHY, 2005, p. 63). E em seu movimento incessante entre o individual e o coletivo na elaboração da experiência e na construção e interpretação do real as memórias envolvem, ainda, as categorias de tempo e espaço.

Tempo que, na concepção de Halbwachs (1990), pode tomar duas formas: uma abstrata, aquela que se vê nos calendários, que é arbitrária, matemática; e outra constituída pelas experiências vividas, que é ao mesmo tempo social e particular. Contudo, as formas de entendimento temporal e a consciência do tempo por meio do entrelaçamento da memória individual e da memória coletiva só podem ser obtidas quando existem acontecimentos (vividos pessoal- mente ou pela coletividade da qual o sujeito se sente parte), personagens e lugares (POLLAK, 1992).

Campo de disputas, intimamente relacionada ao tempo vivido, a memória está também associada ao espaço onde ocorrem as experiências. As lembranças, além de se vincularem às vivências, habitualmente associam-se à terra, à arquitetura, aos rios, às montanhas, às árvores etc. Seria impossível rememorar o passado caso algumas de suas características não se conservassem materialmente. Em contraposição ao tempo, que oferece continuamente a idéia da mudança, o espaço no qual se vive evoca permanência e estabilidade (HALBWACHS, 1990). Com efeito, o espaço sempre é marcado pelo grupo que o habita, pois todas as ações dos seus membros se traduzem em transformações de ordem espacial. Os costumes e as práticas estão inscritos materialmente no meio no qual se vive, pois quando um grupo está inserido numa parte do espaço, ele a transforma à sua imagem, ao mesmo tempo em que se sujeita e se adapta às coisas materiais que a ele resistem (IBIDEM, $\mathrm{p}$. 133). O espaço é, neste sentido, sempre fonte de testemunho e linguagem (SCHMIDT; MAHFOUD, 1993).

Entrementes, embora as narrativas se tornem possíveis pela expressão singular de cada narrador, elas derivam igualmente dos elos existenciais comuns entre indivíduos, os quais renovam pertencimentos sociais por meio delas. As narrações ou histórias orais formam parte daquilo que Halbwachs (1990) chamou de memória coletiva. Para o autor, a memória seria sempre produto social e não individual e, sobretudo, seria um diferenciador comum de um conjunto de pessoas, pois fundamenta e reforça sentimentos de pertencimento e de fronteiras entre os grupos. No entanto, o conteúdo narrado depende [sempre] de quem fala e para quem se fala (MELLO, 2008 , p. 45). Ainda que a memória coletiva seja importante fenômeno social, o passado é construção complexa plena de negociações e conflitos; ele não pode ser evocado de modo idêntico pelas pessoas, pois é criado e recriado com base na experiência singular, em sua interpretação e nas negociações de representações que são, muitas vezes, conflitantes entre si e geradoras de angústias.

Além disso, as histórias narradas nunca se encerram definitivamente, pois uma torna-se ensejo de outra, que desencadeia uma outra, em movimento sem fim. De acordo com Benjamin (1993), a vantagem da narração é que um acontecimento vivido é finito, ou pelo menos encerrado na esfera do vivido, ao passo que o acontecimento lembrado é sem limites, porque é apenas uma chave para tudo o que veio antes e depois (p. 37). As narrações, contudo, nunca são neutras, na medida que a memória coletiva pode ser uma imposição, uma forma específica de dominação ou violência 
simbólica. Sob uma memória coletiva hegemônica, organizada verticalmente, podem co-existir memórias coletivas subterrâneas, marginalizadas ou minoritárias. A memória é, portanto, uma disputa de valores e de prevalência de pontos de vista (POLLACK, 1989, 1992).

\section{Método história oral de vida}

A evocação da memória para a transmição do vivido por meio das narrativas constitui a principal matéria de estudos cujo método é a história oral de vida. Não obstante, nesse tipo de pesquisa também devem ser considerados os silêncios, os esquecimentos, as reiterações, a linguagem não verbal e o cotejamento com fontes escritas e imagéticas. Tudo isso comporá os dados de análise. Contudo, a memória presente nos relatos orais não é sinônimo de História Oral. A passagem daquela etapa para esta se dá por meio da aplicação rigorosa do método, que é um recurso moderno usado para elaboração de documentos, arquivamentos e estudos referentes à experiência social de pessoas e de grupos (MEIHY, 2005).

Meihy (2005) categoriza a História Oral em três tipos principais: história oral de vida, história oral temática e tradição oral. Os dois últimos gêneros não serão abordados nesse artigo, mas de modo geral referem-se, respectivamente, a um estudo que pretende compreender uma temática específica, definida como foco central, e a um estudo muito próximo da etnografia, que busca detalhar o cotidiano de um grupo, os seus mitos, rituais e visão de mundo, dando ênfase à história e a práticas sociais de comunidades específicas e a sua cadeia de transmissão. A história oral de vida, por sua vez, trata-se da narrativa da experiência de vida de uma pessoa (IBIDEM, p.147). É o retrato de uma pessoa cuja trajetória é significativa para a compreensão de eventos, períodos e de práticas culturais e históricas, cuja trajetória é registrada e analisada num esforço para deslindar interações entre percursos individuais e processos coletivos.

Nessa visão, a pessoa que narra sua trajetória é um interlocutor com quem se estabelece uma relação de cooperação, criando, desta maneira, a possibilidade de uma relação dialogada. Busca-se construir uma relação de colaboração e, por isso, adota-se o termo colaborador(a) em substituição a entrevistado ou informante, o qual deixa de ser considerado um objeto de conhecimento para coconduzir conjuntamente com o(a) pesqiusador(a) o registro de sua história.

O procedimento fundamental da construção dos dados na história oral de vida é a entrevista, uma das etapas essenciais de projetos baseados neste método.
Didaticamente, esse processo pode ser dividido em préentrevista, entrevista propriamente e pós-entrevista. A primeira corresponde a uma preparação na qual se realiza os primeiros contatos e aproximações com o(a) colaborador(a) e com o seu contexto, além de ser o momento quando se explica o projeto de pesquisa e se estabelece o processo de colaboração. Busca-se, então, marcar o encontro para a gravação da história de vida. Essa etapa requer bastante estudo e planejamento, pois, além de ser o início do vínculo com aquele que dará substância ao estudo, é momento em que se reúne informações e conhecimentos para que se consiga manter um diálogo fluente com o(a) colaborador(a). Caso não conheça previamente alguns elementos de sua trajetória, dificilmente o(a) pesquisador(a) conseguirá aprofundar os temas tratados.

A entrevista, por seu turno, é o ponto central do estudo, a qual deve ser caracterizada por um ambiente afável, de modo que a pessoa possa narrar sua história sem constrangimentos. Ainda que em interação, as interferências do(a) pesquisador(a) precisam ser mínimas. É a hora e a vez do(a) colaborador(a) expressar-se, o qual deve estar em condições para abordar situações pessoais, para falar de seus sentimentos, sonhos e desejos. Nesse momento, é fundamental esclarecê-lo(a) sobre a importância de sua contribuição, bem como explicar as etapas do projeto e os cuidados éticos adotados. É igualmente essencial dar continuidade ao processo, oferecendo constantes devolutivas às pessoas envolvidas na pesquisa. Por fim, tem-se a pós-entrevista que é o trabalho do(a) pesquisador(a) de organizar e realizar o tratamento das entrevistas registradas. O tratamento das entrevistas compreende, como sugere Meihy (2005), três procedimentos: transcrição, textualização e transcriação - etapas complementares que se referem respectivamente a:

1. Transcrição: processo rigoroso, longo e exaustivo de passagem inicial do oral ao escrito. Para alguns pesquisadores, trata-se de operação de caráter puramente técnico, por vezes relegado a outros. No entanto, na perspectiva apresentada, a transcrição é de grande importância para a construção e análise das histórias de vida, principalmente por sua natureza reiterativa;

2. Textualização: etapa na qual as perguntas do pesquisador(a) são retiradas ou adaptadas às falas dos colaboradores. Há igualmente rearranjos a partir de indicações cronológicas e temáticas. Desse modo, busca-se facilitar a leitura do texto por meio de conformações às regras gramaticais vigentes e da supressão de partículas repetitivas, sem valor analítico, típicas 
do discurso oral. O objetivo é o de possibilitar uma melhor compreensão da narrativa;

3. Transcriação: refere-se a incorpração de elementos extra-textos na composição das narrativas dos colaboradores. Procura-se recriar o contexto da entrevista no documento escrito. Mais do que uma tradução, tenta-se elaborar uma síntese do sentido percebido pelo(a) pesquisador(a) além da narrativa e performance do colaborador(a).

O processo é encerrado com a validação pelo(a) colaborador(a) do documento final. Há, portanto, interferência explítia do(a) pesquisador(a) no texto, que é refeito conforme sugestões, alterações e acertos combinados com o(a) colaborador(a) nos momentos de conferência da narrativa textualizada.

\section{Pesquisa em Terapia Ocupacional e o método história oral de vida: aproximações}

Historicamente, a pesquisa em Terapia Ocupacional no Brasil tem preocupado-se em contextualizar sujeitos e comunidades buscando oferecer uma atenção comprometida e integral (LOPES et al., 2002; BARROS, 2004a; BELLENZANI; MALFITANO, 2006). No entanto, ainda é necessário dar maior profundidade às reflexões para a fundamentação das práticas desenvolvidas. Tal trabalho poderá qualificá-las para transformar realidades e para desenvolver soluções de conflitos e problemáticas relevantes (BARROS, 2004b).

A pesquisa científica não deve ser vista como um ato isolado, como uma ação neutra, pois sempre está vinculada a uma perspectiva e visão de mundo. A pesquisa carrega em si responsabilidades e é parte do processo social em que se insere. E o método da história oral de vida pode ser uma opção para se pesquisar de modo ético e interativo, pois a própria tessitura do trabalho carrega consigo um caráter de produção partilhada do conhecimento. Além disso, redimensiona a relação de poder entre o pesquisador(a) e o(a) colaborador(a) para que se aproxime o máximo possível da horizontalidade.

Por outro lado, o método possibilita que um grupo possa se reconhecer nas histórias narradas pelos seus membros, possibilitando a apropriação da memória coletiva e a adoção de identidades mobilizadoras na luta por direitos. Da mesma forma, a ocultação e silenciamento de possíveis injustiças históricas e sociais às quais as pessoas são vítimas podem ser percebidos e elaborados, tornando-se integrante da consciência do grupo. Assim, as histórias singulares podem ser inseridas numa esfera mais ampla que as conectem a experiências similares e a outros espaços sociais e políticos. A aplicação desse método pode igualmente favorecer a expressão de pessoas e grupos silenciados pela história oficial, permitindo a construção de novas perspectivas e possibilidades de mudanças. Ele fornece, portanto, um rico campo para estudos, em especial para aqueles relacionados aos segmentos que são alvos prioritários das ações da terapia ocupacional.

Nesse sentido, a história oral de vida pode fortalecer a pesquisa em terapia ocupacional tanto pelo rigor como pela participação das pessoas e grupos envolvidos nos estudos do campo. O método pode ainda ser adotado na prática profissional, como maneira de proceder e de interagir na construção de projetos de vida, de modo que favoreça o desvelamento de barreiras simbólicas e sociais que agem contra as positividades de transformações individuais e coletivas almejadas. Produzir história é, portanto, fundamental para que narrativas minoritárias - e que se produzem nas próprias margens - possam surgir e colaborar para a desnaturalização das narrativas hegemônicas.

SILVA, V. P.; BARROS, D. D. Oral method life history: contributions for the qualitative research in occupational therapy. Rev. Ter. Ocup. Univ. São Paulo, v. 21, n. 1, p. 68-73, jan./abr. 2010.

\begin{abstract}
Oral history of life is one of the methods that constitute the qualitative research field, witch is concerned with the meanings and the senses of actions and relationships between people or groups. This article describes and analyses the contributions that this method - systematized in Brazil manly by the historian Jose Carlos Sebe Bom Meihy and colleagues - can provide to the research in occupational therapy and related fields. Thus, this study presents a discussion about memory, a description of that method, to finally discuss links between the research in Occupational Therapy and the oral history of life.
\end{abstract}

KEY WORDS: Narratiion. Memory. Research/methods. Qualitative research. Therapeutic human experimentation/history. 
SILVA, V. P.; BARROS, D. D. Método história oral de vida. Rev. Ter. Ocup. Univ. São Paulo, v. 21, n. 1, p. 68-73, jan./abr. 2010.

\section{REFERÊNCIAS}

BARDIN, L. Análise de conteúdo. Lisboa: Edições 70, 1997.

BARROS, D. D. Histórias narradas, histórias vividas: crises pessoais e transformações sociais em uma localidade negroafricana. Estudos Afro-Asiáticos, v. 26, p.87-110, 2004a. BARROS, D. D. Terapia ocupacional social: o caminho se faz ao caminhar. Rev. Ter. Ocup. Univ. São Paulo, v. 15, n. 3, p.90-97, 2004b.

BARROS, D. D. Itinerários da loucura em territórios Dogon. Rio de Janeiro: Fiocruz, 2008.

BELlenZANi, R.; MALFitANO, A. P. S. Juventude, vulnerabilidade social e exploração sexual: um olhar a partir da articulação entre saúde e direitos humanos. Saúde Sociedade, v. 15, p. 115-130, 2006.

BENJAMIN, W. Obras escolhidas I: magia e técnica, arte e política. São Paulo: Brasiliense, 1993.

BOSI, E. Memória e sociedade: lembranças de velhos. São Paulo: Cia das Letras, 1994.

BOURDIEU, P. A ilusão biográfica. In: AMADO, J.; FERREIRA, M. M. (Coord.). Usos e abusos da história oral. Rio de Janeiro: Ed. FGV, 2000. p. 183-191.

BRIOSCHI, L. R.; TRIGO, M. H. B. Relatos de vida em ciências sociais: considerações metodológicas. Ciênc. Cult., v. 39, n. 7, 1987, p. 631-7.

BRUNELLO, M. I. B. Loucura: um processo de desconstrução da existência. Rev. Ter. Ocup. Univ. São Paulo, v. 9, n. 1, p. 1412, 1998.

FERNANDES, F. Tiago Marques Aipobureu: um bororo marginal [1946]. Tempo Social, v. 19, n. 2, p. 293-323, 2007.

GALVANI, D. Pessoas em situação de rua: itinerários e estratégias na construção de redes sociais e identidades. 261f. Dissertação (Mestrado em Ciências da Reabilitação) - Faculdade de Medicina, Universidade de São Paulo, São Paulo, 2008.

HALBWACHS, M. A memória coletiva. São Paulo: Vértice, 1990.

LEWIS, O. Os Filhos de Sanchez. Lisboa: Moraes Editores,
1979.

LOPES, R. E.; et al. História de vida: a ampliação de redes sociais de suporte de crianças em uma experiência de trabalho comunitário. Mundo Saúde. , v.26, p.426-434, 2002.

MÁRQUEZ, G. G. Viver para contar. Rio de Janeiro: Record, 2003.

MEIHY, J. C. S. B. Manual de história oral. São Paulo: Loyola, 2005.

MEIHY, J. C. S. B.; HOLANDA, F. História oral: como fazer, como pensar. São Paulo: Editora Contexto, 2007.

MELLO, M. M. Mutações de olhar: as vias de diálogo entre o campo e o arquivo. Sociedade Cultura, v.11, n.1, p. 41-49, 2008.

MINAYO, M. C. S. O desafio do conhecimento: pesquisa qualitativa em saúde. São Paulo: Hucitec, 2007.

PIEROTE-SILVA, V. Deslocamentos e histórias de vida: trajetória da comunidade quilombola Riacho das Pedras atingida pela construção da Barragem Luiz Vieira em Rio de Contas-BA. 170f. Faculdade de Medicina, Universidade de São Paulo, São Paulo; NIME-USP; FAPESP, 2008 (Relatório de pesquisa).

POLLAK, M. Memória, esquecimento, silêncio. Estudos Históricos, v. 2, n. 3, p. 3-15, 1989.

POLLAK, M. Memória e identidade social. Estudos Históricos, v. 5 , n. 10 , p. 200-212, 1992.

QUEIROZ, M. I. Relatos orais: do "indizível" ao "dizível". In: SIMSON, O. R. M. von (org.) Experimentos com histórias de vida: Itália-Brasil. São Paulo: Vértice, 1988.

QUEIROZ, M. I.; MAHFOUD, M. Halbwachs: memória coletiva e experiência. Psicologia USP, v. 4, n. 1/2, p. 285-298, 1993.

THOMAS, W. I.; ZNANIECKI, F. El campesino polaco em Europa y en América. Madri: Boletim Oficial del Estado/Centro de Investigaciones Sociológicas, 2004.

THOMPSON, P. A voz do passado: história oral. São Paulo: Paz e Terra, 1992. 